\title{
COMPARING FISHERMEN QUALITY OF LIFE BASED ON THEIR EXPECTATION TOWARD MASLOW'S HIERARCHICAL NEEDS PRIORITY
}

\author{
Mayta Secandina Putri \\ maytasecandinaputri@gmail.com
}

\begin{abstract}
This study is aimed at finding out whether fishermen quality of life would differ if their expectation toward hierarchical needs such as physiological, safety, love belonging, self esteem, and self-actualization, differ also based on they put differently as priority. A survey method used by involving 73 fishermen as a sample. Two instruments were measuring quality of life and Maslow's Needs. Instruments reliability are high and data analysed by correlational analysis, chi square, and verify by applying $F$ and $t$-test. Research results show that around $80 \%$ of fishermen put physiological needs as the most priority, but not followed by safety need. It has been followed by love belonging as second priority, then safety, self-esteem, finally self-actualization. It is also found that there is no significant differences of quality of life between fishermen expectation, whether they put needs as priority or not. It could be concluded that fishermen expectation toward their needs can not be used in analysing the effect of needs on quality of life and needs are not a good predictor as well. The surprising finding is that fishermen from this area put belonging as a second hierarchy.
\end{abstract}

Key Words: Quality of Life, Hierarchical Needs, Life Expectancy, Reliability. 


\section{PENDAHULUAN}

Pada dasarnya kualitas manusia mencakup kualitas manusia sebagai individu maupun secara keseluruhan, baik aspek jasmani maupun rohaninya. Kualitas penduduk pada hakekatnya mengungkapkan keadaan kelompok manusia yang hidup dalam suatu daerah pada saat tertentu. Sejalan dengan hal ini maka cara pengukurannya dilakukan berdasarkan atas angka rata-rata per jumlah penduduk dalam waktu tertentu. Kualitas penduduk meliputi kualitas fisik dan non fisik yang menjadi prasayarat untuk mencapai produktivitas kerja yang tinggi. Bagi masyarakat di bidang perikanan di Indonesia untuk menetapkan indikator kualitas hidup nelayan menggunakan indikator Indeks Pembangunan Manusia (IPM) atau Human Development Index (HDI) nelayan.

Bekerja merupakan salah satu cara manusia untuk memenuhi kebutuhannya dan mempertahankan kelangsungan hidupnya. Setiap manusia senantiasa dilekati motivasi untuk bertanggung jawab terhadap pemenuhan beragam kebutuhannya, baik kebutuhan fisik, sosial, maupun integratif. Maslow menunjukkan bahwa perilaku manusia dimotivasi oleh hirarki kebutuhan. Menurut Eysenck (2009:56) ada dua asumsi utama; (1) Manusia memiliki berbagai kebutuhan yang memotivasi mereka, dan (2) kebutuhan individu khusus bervariasi dari waktu ke waktu. Teori kebutuhan yaitu teori hirarki kebutuhan Maslow. Menurut Maslow (1970:35) terdapat 5 (lima) kebutuhan pokok manusia, yang terdapat pada piramida hirarki kebutuhan, yaitu :1) Physiological needs; 2) Safety needs; 3) Belongingness and Love needs; 4) Self Esteem Needs; dan 5) Self actualization needs. Maslow mengusulkan bahwa ada beberapa tingkat kebutuhan yang harus berusaha untuk dipenuhi seseorang sebelum mencapai tingkat tertinggi kebutuhan. 
Muncar adalah salah satu kecamatan di Kabupaten Banyuwangi, Propinsi Jawa Timur. Terletak di bagian timur Kabupaten banyuwangi, sekitar $35 \mathrm{~km}$ dari pusat pemerintahan Banyuwangi, dan berbatasan dengan Selat bali. Kecamatan ini memiliki 10 desa dengan luas keseluruhan $\pm 8.509,9$ ha. Muncar termasuk pemukiman pantai dengan medan wilayahnya relatif rendah dan dataran tingginya berkisar antara $1-3,7$ meter diatas permukaan laut. Muncar memiliki pantai dan laut yang potensial yang menjadi sumber kehidupan bagi masyarakat.

Laut dan pantai Muncar memiliki nilai yang sangat penting bagi masyarakatnya, karena laut dan pantai menjadi sumber penyokong mereka untuk memenuhi kebutuhan dan juga mempengaruhi kehidupan sosial masyarakat. Jika laut atau pantai rusak maka kehidupan masyarakat juga akan terganggu dengan tidak adanya sumber pemenuhan kebutuhan.

WHO mendefinisikan Kualitas Hidup yaitu persepsi dari individu mengenai posisi kehidupan mereka saat ini dan persepsi individu ini dapat dipengaruhi oleh budaya dan sistem nilai dimana individu tinggal. Ini adalah konsep yang luas mulai terpengaruh dengan cara yang kompleks dengan kesehatan seseorang fisik, keadaan psikologis, tingkat kemandirian, hubungan sosial, keyakinan pribadi dan hubungan mereka dengan fitur yang menonjol dari lingkungan mereka. (http://www.who.int/mental_health) Sedangkan Menurut Redclife (2000:75), The quality of life are health- and environment-related - noise, air quality, housing standards, occupational health, food safety, etc.

Kualitas Hidup (Quality of Life) menurut Costanza (http;//www.costanza, et al. Qol. 2008.com/) adalah sejauh mana kebutuhan manusia yang tujuannya telah terpenuhi dalam kaitannya dengan persepsi pribadi atau kelompok. Kebutuhan manusia merupakan kebutuhan dasar untuk subsistence (penghidupan), reproduction 
(reproduksi), security (keamanan), affection (kasih sayang), understanding (pengertian), participation (partisipasi), leisure (waktu luang), spirituality (spiritual), creativity (kreativitas), identity (identitas), freedom (kebebasan). Hubungan antara manusia dengan kebutuhan dan kepuasan yang dirasakan oleh masing-masing individu dapat dipengaruhi oleh kapasitas mental, konteks budaya, informasi, pendidikan, dsb.

Maslow (1970:35) mengembangkan teori tentang bagaimana semua motivasi saling berkaitan. la menyebut teorinya sebagai "hirarki kebutuhan". Kebutuhan ini mempunyai tingkat yang berbeda-beda. Ketika satu tingkat kebutuhan terpenuhi atau mendominasi, orang tidak lagi mendapat motivasi dari kebutuhan tersebut. Selanjutnya orang akan berusaha memenuhi kebutuhan tingkat berikutnya.

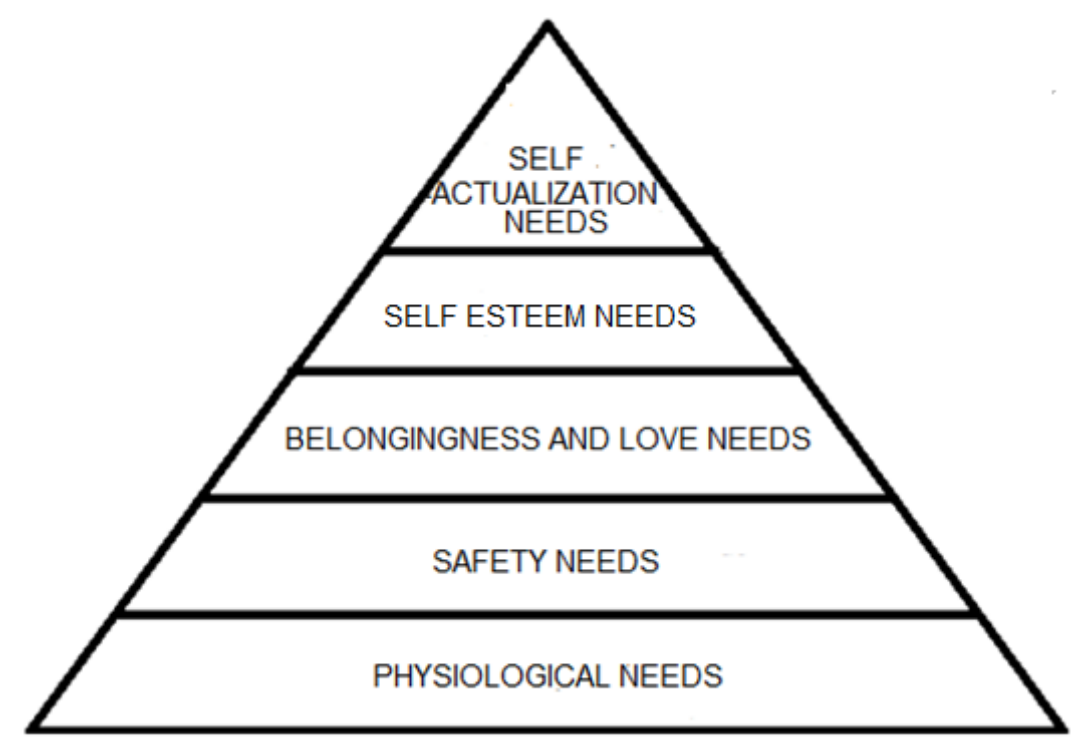

Gambar 1. Piramida Hirarki Kebutuhan menurut Maslow

(Sumber: Abraham H. Maslow, Motivation and Personality, 1970)

Menurut Maslow (1970: 36) Kebutuhan fisiologis adalah kebutuhan manusia yang paling mendasar untuk mempertahankan hidupnya secara fisik, yaitu kebutuhan akan makanan, minuman, dan seks,. Seseorang yang mengalami kekurangan 
makanan, harga diri, dan cinta, pertama-tama akan mencari makanan terlebih dahulu. Bagi orang yang berada dalam keadaan lapar berat dan membahayakan, tak ada minat lain kecuali makanan. Bagi masyarakat sejahtera jenis-jenis kebutuhan ini umumnya telah terpenuhi. Seperti menurut Feist Jess (2013: 257) bahwa "The most basic needs of any person are physiological needs, including food, water, oxygen, maintenance of body temperature, and so on. Physiological needs are the most prepotent of all". Carlson menyatakan (1993:556) bahwa "Physiological needs include the needs for food, water, warmth, and sexual contact. Deprivation of physiological needs causes illness".

Segera setelah kebutuhan dasar terpuaskan, muncullah apa yang digambarkan Maslow (1970: 39) sebagai kebutuhan akan rasa aman atau keselamatan. Maslow mendefinisikan safety needs (kebutuhan rasa aman) yaitu kebutuhan keselamatan (keamanan; stabilitas; ketergantungan, perlindungan, kebebasan dari rasa takut, dari, kecemasan dan kekacauan). Kebutuhan untuk struktur, ketertiban, hukum, batas; kekuatan dalam pelindung, dan sebagainya). David (1998: 366) menjelaskan bahwa "Safety needs Need to feel that the world is organized and predictable; need to feel safe, secure, and stable". Sedangkan menurut Rathus (1993: 340) bahwa kebutuhan keselamatan meliputi perlindungan dari lingkungan melalui perumahan dan pakaian; keamanan dari kejahatan dan kesulitan keuangan. Dan pendapat Fieldman (2003: 254) bahwa kebutuhan keselamatan datang berikutnya dalam hirarki Maslow menunjukkan bahwa orang perlu lingkungan yang aman agar dapat berfungsi secara efektif. Kebutuhan fisiologis dan keamanan menyusun kebutuhan yang lebih rendah.

Pada tingkat kebutuhan ini, dan belum pernah sebelumnya, orang akan sangat merasakan tiadanya sahabat, kekasih, isteri, suami, atau anak-anak. la haus akan relasi yang penuh arti dan penuh kasih dengan orang lain pada umumnya. la 
membutuhkan terutama tempat (peranan) di tengah kelompok atau lingkungannya, dan akan berusaha keras untuk mencapai dan mempertahankannya. Menurut Carlson (1993: 364) , Needs for belongingness and love include a striving for strong interpersonal relations with a lover and with a family group or clan. Prolonged deprivation of the needs for belongingness and love lead to feelings of rejection and loneliness.

Menurut Maslow (1970:39), semua orang dalam masyarakat (kecuali beberapa kasus yang patologis) mempunyai kebutuhan atau menginginkan penilaian diri yang mantap, mempunyai dasar yang kuat, dan biasanya bermutu tinggi, akan rasa hormat diri atau harga diri. Carlson (1993: 364) berpendapat bahwa, "Need for esteem includes the need to feel competent and in control of one's own life (self-esteem) and a desire to be well regarded by other people. A person who fails to gratify the need for esteem will develop feelings of inferiority and helplessness".

Menurut Maslow, setiap orang harus berkembang sepenuh kemampuannya. Kebutuhan manusia untuk bertumbuh, berkembang, dan menggunakan kemampuannya disebut Maslow sebagai aktualisasi diri. Self-actualization needs (Kebutuhan aktualisasi diri) merupakan kebutuhan yang tertinggi tingkatannya dalam hirarki kebutuhan. Jika kebutuhan ini dapat terpenuhi dengan baik, seseorang dapat melaksanakan kodratnya dalam semua aspek kehidupan sehingga menjadi figur tertentu. Santrock (2009:461) menyatakan bahwa "Self-actualization the highest and most elusive of Maslow's needs, is the motivation to develop one's full potential as a human being. In Maslow's view, self actualization is possible only after the lower needs have been met". Lefton (1997:308) juga menyatakan bahwa ktualisasi diri adalah tingkat akhir perkembangan psikologis di mana individu berusaha mewujudkan potensi 
yang unik dalam dirinya, untuk mencapai segala sesuatu yang mereka mereka mampu mencapai.

\section{METODOLOGI PENELITIAN}

Metode yang digunakan yaitu metode survey. Dalam penelitian ini yang dijadikan sampel sebanyak 73 nelayan di Muncar, Kabupaten Banyuwangi dengan menggunakan teknik area random sampling.

\section{HASIL}

Berdasarkan hasil penelitian didapatkan temuan- yaitu sebagai berikut:

1. Hasil penelitian menemukan bahwa urutan prioritas berbeda dengan teori Maslow, dengan urutan prioritasnya yaitu Physiological Needs, Belongingness and Love Needs, Safety Needs, Self Esteem Needs dan Self Actualization Needs.

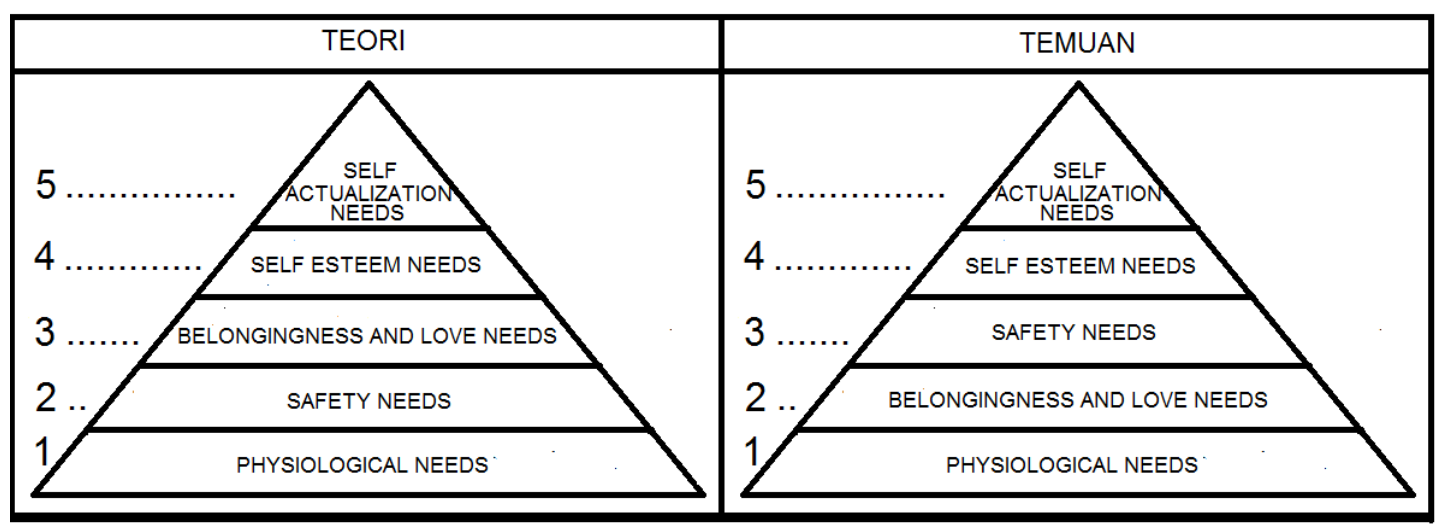

\section{Gambar 2. Temuan Hirarki Kebutuhan Maslow di Muncar}

Pada uji one way anova terdapat 5 kelompok data variabel kualitas hidup

nelayan (yang didasarkan pada Physiological Needs, Safety Needs, Belongingness and Love Needs, Self Esteem Needs, dan Self Actualiation Needs). dengan F hitung $=0,457<$ $F_{\text {tabel }}=2,42$, maka dapat disimpulkan bahwa $\mathrm{H}_{0}$ diterima. $\mathrm{Hal}$ ini berarti model analisis varians satu jalan memiliki rata-rata yang sama (homogen). 
2. Terdapat interkorelasi antara kebutuhan satu dengan kebutuhan lainnya bagi para nelayan yang dijelaskan pada Tabel 1 berikut ini:

Tabel 1. Hubungan interkorelasi antara Kebutuhan Maslow (Physiological Needs, Safety Needs, Belongingness and Love Needs, Safety Needs, dan Self Actualization Needs)

\begin{tabular}{|c|c|c|c|c|c|c|}
\hline Variabel & $X_{1}$ & $\mathrm{X}_{2}$ & $\mathrm{X}_{3}$ & $\mathrm{X}_{4}$ & $X_{5}$ & $\mathrm{Y}$ \\
\hline $\mathrm{X}_{1}$ & 1 & $0,419 * *$ & $0,471^{* *}$ & $0,412^{* \star}$ & 0,030 & $0,643^{* \star}$ \\
\hline$X_{2}$ & $0,419^{* *}$ & 1 & 0,098 & $0,324^{\star *}$ & 0,119 & $0,533^{\star *}$ \\
\hline$X_{3}$ & $0,471^{\star *}$ & 0,098 & 1 & $0,286^{*}$ & 0,146 & $0,486^{\star \star}$ \\
\hline$X_{4}$ & $0,412^{\star \star}$ & $0,324^{\star *}$ & $0,286^{\star \star}$ & 1 & $0,234^{*}$ & $0,765^{\star *}$ \\
\hline$X_{5}$ & 0,030 & 0,119 & 0,146 & $0,234^{*}$ & 1 & $0,331^{* *}$ \\
\hline$Y$ & $0,643^{* *}$ & $0,533^{* *}$ & $0,486^{* *}$ & $0,765^{\star *}$ & $0,331^{* *}$ & 1 \\
\hline
\end{tabular}

Keterangan:

${ }^{* *} \quad=$ sangat signifikan pada taraf nyata $\alpha=0,01\left(r_{\text {hitung }}>r_{\text {tabel }}=0,296\right)$

* $\quad=$ signifikan pada taraf nyata $\alpha=0,05\left(r_{\text {hitung }}>r_{\text {tabel }}=0,227\right)$

$\mathrm{X}_{1} \quad=$ Physiological Needs

$\mathrm{X}_{2}=$ Safety Needs

$\mathrm{X}_{3}=$ Belongingness and Love Needs

$\mathrm{X}_{4} \quad=$ Self Esteem Needs

$\mathrm{X}_{5} \quad=$ Self Actualization Needs

3. Terdapat hubungan positif antara Kebutuhan Maslow (Physiological Needs, Safety Needs, Belongingness and Love Needs, Self Esteem Needs, dan Self Actualization Needs) dengan Kualitas Hidup nelayan dengan thitung $=14,25>$ tabel $=1,67$ dengan kontribusi variabel $\mathrm{X}$ dengan $\mathrm{Y}$ sebesar $74,1 \%$ dapat dijelaskan dengan persamaan regresi $\hat{Y}=54,35+0,47 X$. Masing-masing variabel akan dijelaskan pada Tabel 4.2 berikut ini:

Tabel 2. Matriks Uji Signifikansi Korelasi

\begin{tabular}{|c|c|c|c|}
\hline $\begin{array}{c}\text { Korelasi } \\
\text { Variabel }\end{array}$ & $\begin{array}{c}\text { Zero Order } \\
\text { Correlation }\end{array}$ & $\begin{array}{c}\text { Fourth Order } \\
\text { Correlation }\end{array}$ & $\begin{array}{c}\text { Kontribusi } \\
(\%)\end{array}$ \\
\hline $\mathrm{X}_{1}$ dengan $\mathrm{Y}$ & $0,643^{* *}$ & $0,401^{* *}$ & $41,3 \%$ \\
\hline $\mathrm{X}_{2}$ dengan $\mathrm{Y}$ & $0,533^{* *}$ & $0,415^{\star *}$ & $28,4 \%$ \\
\hline $\mathrm{X}_{3}$ dengan $\mathrm{Y}$ & $0,486^{* *}$ & $0,328^{* *}$ & $23,6 \%$ \\
\hline $\mathrm{X}_{4}$ dengan $\mathrm{Y}$ & $0,765^{* *}$ & $0,699^{* *}$ & $58,5 \%$ \\
\hline $\mathrm{X}_{5}$ dengan $\mathrm{Y}$ & $0,331^{* *}$ & $0,313^{* *}$ & $10,9 \%$ \\
\hline
\end{tabular}

\section{Persamaan Regresi:}

$\hat{\mathrm{Y}}=79,01+1,48 \mathrm{X}_{1}$

$\hat{Y}=85,76+0,86 X_{2}$

$\hat{Y}=69,18+1,25 X_{3}$

$\hat{Y}=79,98+1,11 X_{4}$

$\hat{Y}=91,91+0,43 X_{5}$ 
Keterangan:

** $\quad=$ sangat signifikan pada taraf nyata $\alpha=0,01\left(r_{\text {hitung }}>r_{\text {tabel }}=0,296\right)$

* $\quad=$ signifikan pada taraf nyata $\alpha=0,05$ ( rhitung $\left.>r_{\text {tabel }}=0,227\right)$

$\mathrm{X}_{1} \quad=$ Physiological Needs

$\mathrm{X}_{2} \quad=$ Safety Needs

$\mathrm{X}_{3} \quad=$ Belongingness and Love Needs

$\mathrm{X}_{4} \quad=$ Self Esteem Needs

$\mathrm{X}_{5}=$ Self Actualization Needs

4. Diantara lima kebutuhan maslow yang memberikan kontribusi paling tinggi terhadap kualitas hidup nelayan adalah Self Esteem Needs yaitu 58,5\%.

\section{KESIMPULAN}

Penelitian ini bertujuan untuk mengetahui kebutuhan apa yang menjadi prioritas utama untuk dipenuhi oleh nelayan berdasarkan hirarki kebutuhan Maslow, untuk mengetahui interkorelasi antara kebutuhan satu dengan kebutuhan lainnya bagi para nelayan, untuk mengetahui apakah kebutuhan-kebutuhan tersebut berhubungan dengan kualitas hidup nelayan dan untuk mengetahui kebutuhan manakah yang paling tinggi memberikan kontribusi pada kualitas hidup nelayan di Pantai Muncar, Kabupaten Banyuwangi.

Pertama, Hasil penelitian di lapangan menunjukkan bahwa terdapat perbedaan kebutuhan nelayan di Muncar dengan teori hirarki Kebutuhan Maslow. Temuan di lapangan menunjukkan bahwa prioritas pertama yang menjadi kebutuhan bagi nelayan adalah Physiological Needs, prioritas kedua adalah Belongingness and Love Needs, prioritas ketiga adalah Safety Needs, prioritas keempat adalah Self Esteem Needs, dan prioritas kelima adalah Self Actualization Needs.

Kedua, terdapat interkorelasi antara kebutuhan satu dengan kebutuhan lainnya bagi para nelayan. Hal ini menunjukkan terdapat keterkaitan antara kebutuhan satu dengan kebutuhan lainnya 
Ketiga, terdapat hubungan positif antara Kebutuhan Maslow (Physiological Needs, Safety Needs, Belongingness and Love Needs, Self Esteem Needs, dan Self Actualization Needs) dengan Kualitas Hidup nelayan. Apabila kebutuhan Maslow makin terpenuhi, maka makin baik kualitas hidupnya.

Keempat, diantara lima kebutuhan maslow yang memberikan kontribusi paling tinggi terhadap kualitas hidup nelayan adalah Self Esteem Needs. Nelayan memiliki harga diri yang tinggi, ingin mendapat pengakuan dari orang lain agar merasa diterima dan dihargai dalam lingkungannya.

Hasil penelitian ini diarahkan kepada upaya peningkatan kualitas hidup nelayan melalui lima kebutuhan Maslow (Physiological Needs, Safety Needs, Belongingness and Love Needs, Self Esteem Needs, dan Self Actualization Needs). Kualitas Hidup nelayan akan meningkat jika didukung oleh lima kebutuhan tersebut. Kebutuhan fisiologis dapat ditingkatkan dengan tercukupinya makan secara teratur (3kali sehari), pakaian dan rumah yang nyaman (tidak bocor). Kebutuhan rasa aman dapat ditingkatkan dengan mendapat jaminan kesehatan. Kebutuhan rasa memiliki dan kasih sayang dapat ditingkatkan dengan cara mempererat hubungan kekerabatan antar nelayan, dan keluarga. Kebutuhan penghargaan dapat ditingkatkan dengan menjadi pemimpin masyarakat. Kebutuhan aktualisasi diri dapat ditingkatkan dengan mengembangkan karir, tidak hanya menjadi nelayan, tetapi mempunyai pekerjaan sampingan. Seseorang dikatakan kualitas hidupnya baik apabila telah tercukupinya dan tercapainya kebutuhan yang dibutuhkannya dalam kehidupannya sehari-hari. Untuk itu seseorang harus memiliki keinginan, harapan, dan tujuan hidup dalam dirinya sendiri untuk meningkatkan kualitas hidupnya. 
Berdasarkan kesimpulan dan implikasi penelitian ini, maka disarankan sebagai berikut: (1) Bagi nelayan diharapkan dapat berupaya untuk meningkatkan kualitas hidupnya melalui peningkatan lima kebutuhan agar dapat tercapainya standar kehidupan yang lebih baik. (2) Bagi peneliti disarankan untuk mengembangkan hasil penelitian ini dengan penelitian selanjutnya. Selain itu untuk penelitian selanjutnya diharapkan menggunakan sampel lebih banyak agar data yang digunakan lebih akurat.

\section{DAFTAR REFERENSI}

Chalson, Neil A. Psychology: The science of Behavior. London: Allyn and Bacon, 1993. Chalson. Psychology: New York: Allyn and Bacon.

Costanza, et al. Quality of life: An approach integrating opportunities, human needs, and subjective well-being, http;//www.costanza, et al. Qol. 2008.com/ (diakses 13 September 2015).

Myers, David G. Psychology. New York: Worth Publisher, 1998.

Eysenck, Michael W. Fundamentals of Physiology. New York: Psychology Press, 2009.

Feist, Jess., Feist, Gregory J., Roberts, Tomi-Ann. Theories of Personality. New York: McGraw Hill, 2013.

Fieldman, Robert S. Essentials of Understanding Psychology. New York: McGraw-Hill, 2003.

Lefton, Lester A. Psychology. USA: Allyn and Bacon, 1997.

Maslow, Abraham H. Motivation and Personality. New York: Harper \& Row, 1970.

Rathus, Spencer A. Psychology. Florida: Harcourt Brace College, 1993.

Santrock, John W. Educational Psychology. New York: McGraw-Hill, 2009.

Whoqol. www.who.int/mental_health (diakses 13 September 2015). 